\title{
Evolving Models of Supplier Involvement in Design: The Deterioration of the Japanese Model in U.S. Auto
}

\author{
Young K. Ro, Jeffrey K. Liker, and Sebastian K. Fixson
}

\begin{abstract}
The U.S. auto industry in the 1990 s was in a state of transition, driven by a rapidly changing environment and attempts to adopt best practices from other automakers. The Japanese supplier management system is regarded as extremely effective in delivering high-quality component systems integrated into the vehicle with short design lead times. American automakers dedicated themselves to reengineering their product development systems, benchmarking the Japanese model, and outsourcing increasing levels of vehicle content and design responsibility. This paper analyzes how these attempts at institutional imitation evolved new approaches to supplier involvement in design in the U.S. auto industry based on interviews conducted during 1998-2001. Although once copying the Japanese model, the United States has chosen a modified approach and developed models distinctively different from the original. The authors identify two dominant supplier management models emerging during this time and a newly emerging hybrid original equipment manufacturer/supplier relationship style. Concepts from organizational design and behavioral economic theories are used to explain observations across industries overtime. Evidence suggests that American automaker practices have not evolved to support the great responsibility being outsourced to suppliers. There are still barriers that create adversarial relationships when a partnership model is required for true integration of design efforts.
\end{abstract}

Index Terms-Automotive, Japanese, module, product development, supplier management, systems integrator.

\section{INTRODUCTION}

I $\mathrm{N}$ TODAY's competitive automobile industry, companies that can rapidly design and produce vehicles with the latest features that customers desire have a competitive advantage. Automakers all over the world are trying to gain a lead in product development. They bring different capabilities and approaches to the market, but they are all seeking to reduce development lead time and hit the market with the right product at the right time. This is particularly important as customers expect more and more products made to order for them. As an example, Toyota introduced the 2007 Toyota Camry six months ahead

Manuscript submitted April 1, 2005; revised January 1, 2006, August 1, 2006, and February 1, 2007. Review of this manuscript was arranged by previous Department Editor R. T. Keller.

Y. K. Ro is with the Department of Management Studies, University of Michigan, Dearborn, MI 48126 USA (e-mail: yro@umich.edu).

J. K. Liker is with the Department of Industrial and Operations Engineering, University of Michigan, Dearborn, MI 48126 USA (e-mail: liker@umich.edu).

S. K. Fixson is with the MIT Sloan School of Management, Cambridge, MA 02142 USA (e-mail: fixson@mit.edu).

Color versions of one or more of the figures in this paper are available online at http://ieeexplore.ieee.org.

Digital Object Identifier 10.1109/TEM.2008.919733 of schedule due to shaving six months off the total concept-todelivery cycle and offered it in early 2006. Customers could then have available features in the Toyota Camry that they would not otherwise have seen in other vehicles until late 2006, giving Toyota a distinctive competitive advantage.

Long seen as slow moving and stable with regard to new product offerings, the automotive industry is becoming a leaner, agile, and more competitive fast-paced industry; exhibiting a faster product development clock speed [1], if you will. Advances in information technology such as e-business initiatives and use of the Internet have brought greater speed of communication and data exchange. Also, the growing popularity of lean manufacturing and Six Sigma programs are resulting in higher quality products, provided at shorter lead times, and produced at lower cost. Since the 1980s (a decade where there was a large emphasis on improving the quality of American-made cars), differences in initial vehicle quality, as measured by $\mathrm{J}$. D. Power \& Associates, between American, Japanese, and even Korean cars, have narrowed considerably. Although there exist some disagreement among reported sources as to just how far the quality gap has closed in recent years, much progress has been made in closing the quality gap, and this has placed greater pressure on automakers to compete based on new features, innovative designs, and long-term durability.

Today, companies in the United States and elsewhere are seeking ways to develop products more quickly and efficiently by considering the efficiency and effectiveness of the total value stream. As companies think in value stream terms, they are identifying their core competencies and outsourcing everything else, including design and development responsibility for major vehicle subsystems. This means completely recasting their relationships with the supply base [2]. The best-practice models for supply chain management from a performance point of view still remain those based on the Japanese keiretsu relationships, characterized by the close ties exhibited between the buying firm [termed original equipment manufacturer (OEM) and refers to automakers such as Ford or General Motors (GM)] and its direct suppliers [3], [4]. In many studies, Japanese automaker plants continue to outperform the U.S. plants from productivity and quality perspectives, two measures of performance that have been used to delineate plant performance [4], [5]. In terms of both final product quality and supplier product quality, the U.S. plants generally perform worse than their Japanese counterparts, although the quality gap has narrowed in recent years [6]. It has been argued that the congruence between organizational values and practices bear a strong relation to organizational 
performance [7], [8]. That being the case, it is easy to see why many U.S. auto companies have been trying to learn from Japanese supply chain management practices and adapting these practices to fit the U.S. context, a process very much in a state of experimentation and change.

The purpose of this paper is: 1) to understand similarities and differences in the evolving models for supplier involvement in design between Japanese and U.S. automotive companies as the U.S. companies are adapting versions of the Japanese model; 2) to use multiple conceptual frameworks that explain the current OEM/supplier relationship trends seen in the U.S. auto industry today; and 3) to describe the basic support systems that need to be in place to support the evolution.

The evolution of supplier involvement in design in the U.S. is more than an issue of the transfer of specific tools and technology, but rather of encompassing fundamental changes in design approaches, commercial relationships, and even institutional arrangements. Such fundamental relationship and institutional changes cannot merely be picked up from Japan and set down in the U.S. The transfer of practices, especially social processes, is much more an adaptation of automakers' interpretations of the Japanese model, and often, due to recontextualization of these processes in a new environment [9], the end result is very different from the starting point in Japan [4]. The research method used for this study included semistructured, qualitative interviews with a broad range of managers and directors in automakers and suppliers. This allowed for an in-depth picture of the dynamics of buyer-supplier relationships, albeit at a slice of time (1998-2001) within this transformation process.

\section{CONCEPTUAL FRAMEWORKS}

\section{A. Theoretical Background}

It is not a goal of this paper to build or test an integrated theory of supplier involvement. Rather, the authors aim to better understand and explain the evolution of supplier involvement in design in the U.S. auto industry by drawing on several conceptual frameworks to help analyze the observed phenomena occurring in the industry.

To start, we consider the economics-based theories of supplier outsourcing that address the fundamental question: "Why do customers outsource some activities and not others?" There is a lengthy literature that includes numerous theories including transaction cost economics, game theory, principal-agent theories, and others that assume the buying firm makes a rational cost-benefit analysis based on perceived benefits and costs of doing the work in-house vs. outside. The basic assumption is that the buyer attempts to maximize expected utility, which takes into account the probability of benefits as compared to the costs, including perceived risks. This is not to say that these models assume perfect rationality. Transaction cost economics, for instance, posits bounded rationality and examines the transaction costs associated with a supplier exploiting any advantage to gain power over the buyer [10]. If we consider the case of a buying firm making a relationship-specific investment in the supplier, then it will be difficult for the buyer to drop the supplier. In addition, the pure market mechanism of competition is weakened, giving the supplier an opportunity to exploit its advantage by charging higher prices to the buyer. The buying firm can deter being exploited by the supplier by doing much of the development and production work in-house through the use of an internal hierarchy to control the activity. Another alternative open to the buyer would be to keep the intellectual property in-house and only outsource commodity work that is easy to resource through market mechanisms. The buyer can also closely monitor the outside supplier to detect any signs of exploitation, an option that serves to increase transaction costs. Principle-agent theory discusses how contracts are written to legally protect the buyer from exploitation [11].

The literature is rich and complex, and we cannot cover all the theoretical nuances in this paper, but for our purposes, these economics-based theories all lead to a common general conclusion: the buyer needs to beware and avoid being placed at the mercy of the outside supplier that will exploit any advantage. These conceptual frameworks are challenged by the Japanese outsourcing model, which seems to be based on a high degree of trust and close bonds between the buyer and supplier [12]. Contracts are not complex, highly sensitive intellectual property is shared with suppliers in the early stages of product development, suppliers and buyers make relationship-specific investments (thus locking buyers into certain suppliers), and buyers seemingly ignore competitive suppliers outside of their small close-knit keiretsu. Recent terms like "relational contracting" are used to explain this hybrid between use of a hierarchy for control and the use of market competition [13], [14].

A somewhat different perspective comes from the resourcebased view of the firm often espoused in the corporate strategy literature [15]. One unique aspect of this family of theories is that unlike transaction cost economics, which focuses on transactions as the unit of analysis, resource-based theories focus on asset ownership, where assets are broadly construed as resources. Resource-based theories posit that intelligent investments by firms in gaining control of assets can provide a sustained competitive advantage [16]. These theories hypothesize that heterogeneity, rarity, lack of available substitutes, and inimitability are the characteristics that determine the value of resources [17]. These theories also hypothesize that assets that create value are firm specific in nature, and that such specificity requires accumulation overtime. We can start to see how the Japanese companies' long-term relationship-specific investments in supplier innovation through early involvement in design can provide a source of competitive advantage.

When looking at the organizational design literature, we take a somewhat different perspective. This literature looks at organizational effectiveness and the requirements for effective task accomplishment. In the case of product development, the problem starts with dividing up a complex intellectual task, such as designing a car, into pieces developed by different parties. However, what is divided up must be reintegrated. As one piece of the vehicle design changes, it has implications for other pieces of the design. Thompson [18] used the concept of task interdependence to look at how different tasks need to be integrated. Pooled interdependence is relatively easy to manage. In this case, each party draws on a central pool of resources or information, and 
relatively little communication between parties is needed. In product development, if we could create a central database that various parties can go to obtain data, and then, input changed data, relatively little interaction is needed across parties. A simple internal functional organization structure works well in this case, with suppliers being viewed as outside functional specialists controlled through rules, contracts, and market mechanisms. The most challenging type of task interdependence for organization design to facilitate is that of reciprocal interdependence, which is more characteristic of the automotive design and development process. When interdependence is reciprocal in nature, a change to one part of the product has immediate ramifications for a change in another part.

Automobiles are complex engineering systems, and any change in the design of one part has implications for the total system. This is true in terms of physical space requirements-make a part in the engine compartment bigger, and some other parts must become smaller. Change the shape of one part and another part's shape must be changed. This is also true in terms of structural stresses--change a door beam's design, and it will affect the performance of the structure, which, in turn, may require changing another structural element to meet stress requirements. Even a vehicle's quietness and smoothness of ride can be affected by a simple change in the treads of a tire or tightening of its vehicle suspension.

Given this complexity, we would say that automobile design is a case of reciprocal interdependence, using Thompson's framework, that requires a high degree of communication as the design is being carried out. One way to reduce this interdependence and move in the direction of pooled interdependence is through the modularization of vehicle components. This was done effectively in the case of computers where various components in the computer, such as the hard drive, could be connected interchangeably. Taking this same principle to the development of an automotible, one can imagine outsourcing an entire instrument panel, where the physical design appearance is prespecified, weight and functionality are prespecified, and connection points are prespecified. This can enable several suppliers to develop a design and competitively bid for the job. The suppliers can input their models into a centralized database where the functionality of the proposed design can be tested. This would, of course, assume that all the interfaces are simple and stable enough to be communicated to the supplier as design specifications. The so-called "black box" approach to design gives the impression that the buyer can specify the space, functional, and interface requirements of the outsourced part, and the supplier can independently design what is inside.

From Galbraith's [19] information processing perspective, the automotive design process poses an issue of task uncertainty. If the task is highly certain with clearly delineated expectations, then the information processing requirements can be dealt with in a vertical hierarchy, and one would expect market mechanisms to efficiently handle task outsourcing. For highly uncertain tasks, high capacity information processing systems require strong organizational coordination mechanisms, as seen in the Japanese partnership model. One effective way to reduce information processing requirements for highly uncertain tasks is by creating simpler self-contained tasks. From this perspective, modularity [20]- [22] allows for the creation of self-contained tasks. This reduces information processing requirements and allows suppliers to work relatively independently, allowing for more controllable and arms-length relationships with suppliers. Dividing the vehicle into disparate outsourced modules allows for the knowledge, information, and processes used in creating the modules to be bundled into divisible, manageable units.

Another organizational design perspective useful in analyzing the evolving models of supplier development is Paul Adler's distinction between coercive and enabling systems of bureaucracy. Adler [23] noted that bureaucracy is often associated with "red tape" and inflexible mechanistic systems. The rigidity of bureaucracy is fine in certain cases-a stable environment with simple, routine tasks. Increasing the rate of change of demands from the environment increases the complexity of tasks, resulting in the need for more organic structures. Yet Adler studied Toyota's joint venture with GM, i.e., NUMMI, which was run using the Toyota Production System, and noticed something different. While the typical GM plant looked like a rigid bureaucracy, NUMMI seemed to have more elaborate rules and standardized procedures. However, this system of rules and controls operated differently than the conventional bureaucracy. It actually enabled flexible responses to problems and encouraged innovation. From this, Adler theorized that there were two kinds of bureaucracy--coercive, like the kind often seen at traditional GM plants, and enabling, like the Toyota Production System seen at NUMMI.

When considering buyer-supplier relations in the American and Japanese auto industries, we notice that the U.S. companies are operating according to the simple utility maximizing logic of the economists--minimize risk, use market mechanisms to motivate suppliers to reduce price, closely monitor suppliers on key performance indicators, and do in-house the complex tasks that create a high degree of dependency on an outside supplier. As a starting point, Japanese auto companies seem to manage their suppliers and product development processes from more of an organizational design perspective. Source relatively whole tasks to outside suppliers, and then, build effective mechanisms for integrating the suppliers into the product development process. In both the American and Japanese cases, automakers appear to use highly bureaucratic systems, but the U.S. approach has been largely coercive, while the Japanese approach has been more enabling.

\section{BACKGROUND}

\section{A. History of the U.S. and Japanese Supplier Management}

The auto industry has arguably led the way in the U.S. in attempting to apply Japanese design and manufacturing methods [4], [24]. The role of suppliers in product development is no exception. The Japanese approach to supplier management has been frequently studied and benchmarked in the past [2], [3], [25]-[29]. It forms the basis for supplier management policies in automotive companies throughout the world. Thus, it is important to accurately understand the Japanese approach to supplier management, and to know what aspects U.S. 
companies are attempting to emulate and how these are being modified to fit the U.S. context.

The picture that emerges from the past literature about supplier management models is one of cooperative partnerships in product development in Japan, predominately among assemblers and first-tier suppliers, and adversarial relationships in the U.S., with suppliers brought on board after most product development is complete [26]. But, with the new supplier management trends occurring in the auto industry in the 1980s and 1990s, a far more complex picture is emerging.

During the middle of the 20th century, W. Edwards Deming, the famous quality expert, came to Japan and helped fuel a quality revolution that brought the Japanese economy to world prominence. He introduced to Japanese managers the concepts of statistical quality control, and it was accepted in Japan with much enthusiasm. During the 1950s, Japanese automakers were vertically integrated much like their U.S. counterparts [30], [31]. However, due to a more organized labor force, lack of capital, and a lack of financing for new capacity, the Japanese automakers began to adopt a subcontracting strategy. By the mid-1960s, 11 Japanese firms had each developed a network of 200-300 direct close suppliers. Overtime, they institutionalized a supply management practice, whereby relationships were governed not primarily by market or hierarchy, but by trust [32]. That is not to say the use of basic contracts were not prevalent in Japanese supplier management practices since contracts represent an expression of the OEM's commitment and specify norms for determining prices, quality standards, ordering and delivery, proprietary rights, and materials supply [33]. But, in addition to these contract mechanisms, Japanese supplier management relationships were strongly bolstered by equity holdings and the tremendous purchasing power of automakers. A practice of dual sourcing for a type of component, while awarding business for a particular vehicle, served to create intense competition within the keiretsu. Eventually, the Japanese automakers got to the point where they gave their suppliers responsibility for the quality of the parts and components that were being produced. In the late 1980s, American automakers took note of the Japanese success and decided that they needed to better utilize the design capabilities of the U.S. supply base.

\section{B. Supplier Involvement in Design}

Following the quality resurgence of the 1980s that resulted in vast quality improvements in American-made automobiles, attention quickly turned upstream to product development. It took until the early 1990s before product development and supplier relationship issues among Japanese automakers began to be studied [2], [25], [34]. As stated by Charles Fine [1] in his book Clockspeed: Winning Industry Control in the Age of Temporary Advantage, "Many more managers are recognizing the strategic importance of a firm's product development process . . . product development is the lifeblood of the company. Substantial investment in streamlining and shortening both the product's development time and its time-to-market has taken precedence over many other programs." Clark and Fujimoto [34] in their book Product Development Performance: Strategy, Organiza- tion, and Management in the World Auto Industry stated that one of the key features of Japanese supplier management was the substantial involvement of suppliers in product development; that the early involvement of suppliers in product development was instrumental in reducing lead time and avoiding production problems downstream that could prove costly [26]. They also reported that "The average Japanese firm had almost double the development productivity, and could develop a comparable product a year faster than the average U.S. firm." Another study performed by Clark and Fujimoto [34] showed that on an average, $20 \%$ of the engineering of new parts were performed by suppliers with 7\% in the U.S., $16 \%$ in Europe, and 30\% in Japan.

As recently as the early 1990s, there were suggestions of movement by the U.S. auto companies toward the Japanese supplier management model [27], [35], but information on how far the U.S. has come in this regard has been quite sketchy [24]. This study observes that the new emerging models in the U.S. of supplier management in product development are taking such concepts as modularity [36] and systems integration [36] to a new level, and adding onto the fundamental Japanese concept. Major systems are being outsourced as if they were self-contained tasks and managed autonomously. Yet, Japanese automakers assume that there are still high degrees of interdependence that must be managed through close communication and coordination with suppliers. At the same time, some of the foundations for partnership and trust so prominent in the Japanese model have never been developed by the U.S. automakers and have deteriorated overtime, giving rise to strengthened coercive bureaucratic features instead of being replaced by more enabling forms of bureaucracy.

\section{OEM/Supplier Relations in U.S. Auto}

When the U.S. automakers studied the supplier management practices of their Japanese counterparts, they began to mimic some of the practices utilized by the Japanese. In the 1990s, some OEMs developed concepts such as "full service suppliers" (e.g., Ford Motor Company), and even certification methods to formalize the capabilities required of these top-tier suppliers. There was much talk among executives within the auto industry of having top-tier suppliers as long-term partners.

In 1992, Jose Lopez was named GM's Vice-President of worldwide purchasing and quickly gained a reputation as a relentless cost-cutter. Lopez gained a reputation for streamlining GM's purchasing operations and made an immediate impact by forcing GM suppliers to dramatically cut prices, a major component in GM's financial turnaround. Suppliers often complained of his aggressive tactics, saying he tore up contracts and shared confidential material with their competitors [37]. Under Lopez, GM would identify cost saving opportunities in the supplier plants and reduce payment to the suppliers accordingly, thus forcing suppliers to make cost reductions in order to keep GM business. Lopez clamped down on inefficiency at GM by rapidly reorganizing GM's massive parts purchasing activities and aggressively promoting the use of Purchased Input Concept Optimization with Suppliers (PICOS) workshops by its suppliers. The PICOS sessions were one-time, multiday workshops 
TABLE I

TRAditional U.S.-JAPAN MOdELS OF SUPPLIER INVOLVEMENT IN DESIGN

\begin{tabular}{|c|c|c|}
\hline Characteristic & U.S. Model & Japan Model \\
\hline Outsourcing: & High vertical integration & High outsourcing \\
\hline Supplier Selection Basis: & Market competition & Develop long-term partnerships \\
\hline Pool of Suppliers: & $\begin{array}{l}\text { Any company with technical } \\
\text { capability }\end{array}$ & Small pool of partners \\
\hline Timing of Involvement in Design: & Late in preproduction stage & Early in conceptual stage \\
\hline $\begin{array}{l}\text { Supplier Role in Product } \\
\text { Development: }\end{array}$ & Execute detailed specifications & $\begin{array}{l}\text { Develop based on fuzzy } \\
\text { requirements }\end{array}$ \\
\hline Expected Supplier Contribution: & Meet specifications & Innovative solutions \\
\hline Determinant of Quality: & $\begin{array}{l}\text { Carefully followed quality } \\
\text { procedures }\end{array}$ & Tightly integrated design solutions \\
\hline Organizational Design Approach: & Hierarchical control & $\begin{array}{l}\text { High horizontal coordination \& } \\
\text { communication }\end{array}$ \\
\hline Bureaucracy: & High coercive & High enabling \\
\hline
\end{tabular}

in which cost reductions were identified. Suppliers were then tasked with continuing the process in order to lower costs throughout GM's supply chain. Lopez used PICOS workshops to pressure suppliers to lower prices across the board. The workshops were vehicles for cost-cutting activities resulting in reductions in investment costs, floor space, direct labor, and setup time. Teams from GM dropped into a supplier, led a workshop, identified cost saving opportunities, and then, expected suppliers to continue this cost cutting across the factory and significantly drop prices to GM. Lopez became infamous for such dramatics as standing on a stage in front of a group of suppliers and tearing up a contract. The message was that nothing was sacred in the drive for cost reduction. In short, Lopez promoted PICOS in order to make GM's suppliers "leaner," thus lowering GM's costs. Very quickly, this cost-cutting, cost-reduction emphasis at GM became nicknamed the "Lopez model," and soon, other OEMs in the industry (outside Japan) wanted the same low prices.

In contrast to the Lopez model, another member of the Big 3, the Chrysler Corporation, under the leadership of Thomas Stallkamp, began to emerge strongly with the partnership model in dealing with their suppliers. Chrysler had made a dramatic reorganization to platform teams--a product-focused organizational structure--to streamline the product development process. Suppliers were to be connected as an integral part of the platform teams, designing in their parts from the early stages. Chrysler started the "extended enterprise" that emphasized long-term contractual relationships with their top-tier suppliers. Chrysler also had the Supplier Cost Reduction Effort (SCORE) program, which was a cost-reduction program to help Chrysler's top suppliers achieve cost savings as well as help Chrysler maintain a supply base of closely knit full service suppliers [38]. The basic premise of the program was for Chrysler and its lead suppliers to reduce system-wide costs without negatively affecting supplier profits. There were a variety of ways to achieve SCORE credits, including cost avoidance. It also involved Chrysler splitting cost savings with its suppliers, which created an incentive for suppliers to strive to make their processes more efficient. Over a 7-year period, the SCORE program was responsible for over $\$ 1$ billion in savings and helped build partnerial business relations with several suppliers [39]. In the words of then President, Thomas Stallkamp, the SCORE program was successful because it was a "communications program, not just a cost-cutting program." By improving communications, Chrysler and its suppliers had developed a system to learn how to help each other.

Due to the success of the extended enterprise and the SCORE program at cost reduction plus positive relationships, other OEMs such as Ford Motor Company started to take steps in adopting a more partnerial relationship style with their top suppliers. Among the Big 3, Chrsyler had created a name for itself as having the most partner-like approach in dealing with their suppliers. As Chrysler grew with the partnership model of supplier management, there was talk and publicity in the industry regarding the mutual benefits of partnerial OEM/supplier relationships [40]. In fact, in the early 1990s, there was a general trend away from short-term contracting with numerous suppliers and so-called "arm's length" relationships [41] and a move toward greater commitment with sole-sourcing and with longer-term contracts in the context of partnerships and alliances with a much more compact supply base [42]. Yet, evidence of adversarial hardball negotiation tactics continued through their period of "partnership," and Chrysler began slipping back to an adversarial model after purchase by Daimler-Benz and replacement of most key executives. One of the contributing factors for this reversion was the discovery that some suppliers were opportunistically charging DaimlerChrysler more than their other Big 3 customers.

The coexistence of the adversarial and partnerial relationship styles coinciding with the merging of the Traditional U.S. and 
TABLE II

U.S. VERSUS JAPANESE SUPPLIER MOdELS By SUPPLIER SERVICE CONTRACTED

\begin{tabular}{|l|c|c|}
\hline \multicolumn{1}{|c|}{ Supplier Service } & U.S. Adversarial Contracting & Japanese Partnerial Contracting \\
\hline Build-to-print component: & Customer dominant & Customer dominant \\
\hline Module Supplier: & Customer at risk & Customer investment \\
\hline System Supplier: & Customer dependent & Partnership model \\
\hline
\end{tabular}

Japanese keiretsu supplier management models in an American context sets the backdrop for this study (see Table 1).

The traditional U.S. adversarial model seems best suited to the purchase of off-the-shelf commodities or relatively simple components that are designed by the OEM release engineer. In that case, suppliers can compete on price and be easily substituted if they are not performing. On the other hand, we would expect that outsourcing to suppliers more complex modules or whole systems in which the supplier takes over design responsibility puts the customer at greater risk. In the case of the purchase of complete modules, the supplier is apt to develop unique manufacturing capabilities that cannot be easily imitated, making switching costs high and putting the customer at risk. Even more serious is sourcing complete system design and manufacturing to suppliers that can actually make the customer highly dependent on the supplier. In such situations, we would expect the customer to keep internal control of the product using the internal hierarchy.

On the other hand, Japanese firms are known to outsource large portions of the vehicle; even modules and systems. Firsttier Japanese suppliers of subsystems have major design responsibility. Not all suppliers are created equal, and for simple buildto-print components, the Japanese customer is clearly dominant. For modules, the customer is making an investment in the supplier and does not seem overly concerned about risk, and for system suppliers, there is more of a partnership model. How can the Japanese customer get away with this? Part of the answer is the keiretsu structure in which the Japanese auto company has equity in the supplier, and therefore, a degree of direct control. In addition, the Japanese automakers have developed a history of mutually beneficial relationships which has fostered a type of fair trade and trust. Table II summarizes the aforementioned descriptions of the U.S. and Japanese supplier models.

So, what happens if the U.S. customer starts to imitate the Japanese model without any equity and in the context of a history of adversarial relationships? This paper addresses that question, and, in the next section, we will develop the research questions in greater detail.

\section{RESEARCH QUESTIONS}

The traditional Japanese supplier management model can be used as both a springboard and a benchmark for U.S. OEM and supplier practices. It exemplifies many of the benefits of the supplier management models emerging in the United States, and it can also serve as a starting point from which the U.S. companies can adopt practices that might be well suited for the global market. With the U.S. OEMs attempting to learn from the Japanese model in auto for nearly 20 years, this paper looks at how this process is unfolding. The main research question addressed in this paper is: How did buyer-supplier relations in the U.S. auto industry change over the decade of the 1990s through 2000 as influenced by the Japanese model? Expanding on this question we will address.

1) How is the Japanese model of supplier integration in product development being transferred and transformed in North America?

2) What changes and events are unfolding as a result of the transfer of the Japanese model to the U.S. context?

3) How does this affect OEM/supplier relationships here in the U.S. today?

\section{Methodology}

To address these basic research questions, an empirical, longitudinal study was conducted based on semistructured interviews with OEMs and suppliers. Between the summers of 1998 and 2001, we conducted extensive interviews about product development with senior engineers, managers, and directors in the design, production, and product development departments of first-tier automotive suppliers. Senior engineers, managers, and directors at the major U.S. automakers (i.e., the Big 3) and a major Japanese automaker were also interviewed for their perspective on the OEM/supplier relationship in product development. The engineers were better able to provide a detailed picture of the role of suppliers in product development, while the managers and directors were better able to provide a macroscopic view of the topic, and to relate it to general trends in the industry. In total, 66 different people were interviewed from among 28 different companies.

For our purposes, first-tier suppliers were defined as those that directly worked with and shipped parts to the assembly, stamping, or engine divisions of the automaker. Suppliers to internal component divisions of automakers or suppliers that primarily supplied other outside suppliers were considered to be second-tier or lower, and were not included in the study. The automotive suppliers interviewed in this study included suppliers responsible for subsystems within both the interior and chassis systems. Door panels, seating, brakes, climate control, fuel systems, steering, and exhaust systems were components and subsystems produced by suppliers involved in our study. Many of the suppliers involved in the study were also responsible for the production of door modules, vehicle front-end modules, and interior cockpit modules on various programs. Several hours of semistructured interviews were conducted with 66 
TABLE III

INTERVIEW SUMMARY TABLE

\section{8-2001 Interview List}

\begin{tabular}{|c|c|c|c|}
\hline $\begin{array}{l}\text { SYSTEM / } \\
\text { MODULE }\end{array}$ & $\begin{array}{l}\text { Number of } \\
\text { Companies }\end{array}$ & $\begin{array}{c}\text { Number of } \\
\text { People }\end{array}$ & $\begin{array}{c}\text { Interview } \\
\text { (Hrs) }\end{array}$ \\
\hline Chassis & 4 & 6 & 8 \\
\hline Exhaust & 2 & 5 & 4 \\
\hline Frame & 2 & 3 & 4 \\
\hline Fuel & 2 & 2 & 4 \\
\hline HVAC & 1 & 2 & 4 \\
\hline Seats & 2 & 6 & 12 \\
\hline Cockpit Module & 6 & 18 & 28 \\
\hline Door Module & 2 & 6 & 4 \\
\hline Front-end Module & 2 & 6 & 6 \\
\hline Suppliers & 23 & 54 & 74 \\
\hline Automakers & 5 & 12 & 16 \\
\hline TOTAL & 28 & 66 & 90 \\
\hline
\end{tabular}

engineering managers, design engineers, and executives from different OEMs and suppliers. Table III summarizes the breakdown of the companies and individuals that were interviewed for the study.

Questions on identical topics were asked of the suppliers and OEMs to gain different perspectives on the research topics. The questions dealt with a variety of topics relating to the roles that both the OEM and suppliers played during the product development process, from product concept, to package quotes, to production launch. Other issues regarding the rising popularity of modularity and systems integration in automotive product design were also addressed, as well as topics specific to the OEM/supplier relationship in product development such as designing in-house, outsourcing, information technology issues, guest engineers, security, and negotiation styles of various OEMs. As the study progressed, it became evident that certain common themes were arising.

\section{RESULTS}

\section{A. Emergence of Modules}

After the first few interviews, it became apparent that many of the important trends surfacing in the suppliers' role in automotive product development dealt with how OEMs and suppliers were addressing the issue of modules and systems in the vehicle. It is important to point out here the differences between a component, module, or system in the automotive context. Based on the interviews conducted, almost one-half (13 out of 28) of the companies interviewed proposed working definitions. These are summarized in Table IV.

For several decades, automobiles were designed and assembled around the use of components, with the components being produced either in-house or outsourced to various suppliers. Many of the systems in an automobile have also been in place for several decades. But, all that began to change in the mid- to late-1990s; the concept of modules began taking prominence in the U.S. automotive industry. What used to be accomplished by the interaction of components was starting to be accomplished by the use and interaction of modules. Since that time, the dominant architectural paradigm in the design and development of automobiles was to have the systems and functions of the vehicle being performed by an interacting combination of components, subassemblies, and modules.

\section{B. Shifting Responsibility}

Another major observation was a shifting of responsibility from automakers to the Tier 1 suppliers as the U.S. OEMs began requiring top-tier suppliers to adopt more and more of what Kamath and Liker [2] call a mature role in not only performing the technical work, but taking substantial responsibility for development, testing, and even managing other suppliers making components of their subsystems. As one Vice-President of a supplier stated, "There has been a significant shift of having the supply base taking leadership roles in benchmarking, marketing vehicle strategy, setting the vehicle package, and styling to reach the targeted consumer base." There was also a growing understanding that so-called "full service" suppliers were expected to manage their own costs in research and development of new technologies and to not expect reimbursement for these costs except through the price per piece of goods shipped long after the R\&D was done.

At the time of the interviews, OEMs were mostly purchasing components and subassemblies for their vehicles. The number of suppliers at this level was as many as 300 for any of the Big 3 American auto suppliers. Only about 50-60 suppliers were considered modular or system-level suppliers supplying larger chunks of the car. All of the OEMs interviewed expressed a desire for their suppliers to move toward a greater level of responsibility, including system and vehicle level testing of their modules and systems.

The desired "full service" supply base that the OEMs were hoping for would involve only a few lead tier 1 suppliers that would be responsible for large chunks of the car and for systemslevel and vehicle-level testing of their products. Then, in turn, these lead suppliers would manage lower tier suppliers. With much of the production and testing being increasingly spun off to the supply base, the OEMs would be able to focus more on the design, assembly, and coordination of overall vehicles.

\section{Lack of Trust}

The third major observation that emerged in the interviews dealt with the lack of trust between the U.S.-based OEMs and suppliers. As much as customers wanted suppliers to take major responsibility for whole chunks of the vehicle, there remained a general lack of trust between them. Some of this was an indirect result of certain cost-reduction policies adopted by OEMs, as well as cases of micromanaging design projects or even changing agreed upon sourcing and target agreements multiple times. One director in the Ford division of a lead Tier 1 interior supplier complained: 
TABLE IV

WORKING DEFINITIONS OF MODULES AND SYSTEMS

\begin{tabular}{|c|c|c|}
\hline Concept & Description & Popular Examples \\
\hline Component & $\begin{array}{l}\text { An individual physical part that can be attached to, or } \\
\text { separated from, a larger composite entity, such as a } \\
\text { sub-assembly or even the vehicle itself. }\end{array}$ & $\begin{array}{l}\text { Door handle } \\
\text { Steering Wheel }\end{array}$ \\
\hline Module & $\begin{array}{l}\text { A physical standardized, self-contained assembly of } \\
\text { automotive components designed for easy installment } \\
\text { into the vehicle as a unit, performing tasks in } \\
\text { conjunction with other components and modules to } \\
\text { support the major functions of the vehicle. }\end{array}$ & $\begin{array}{c}\text { Door module } \\
\text { Cockpit module }\end{array}$ \\
\hline System & $\begin{array}{l}\text { An entity defined by the function it performs and is } \\
\text { part of an organized, coherent, and interacting set of } \\
\text { functions constituting the overall functioning of the } \\
\text { vehicle as a complex whole. In some cases, it can be } \\
\text { determined by the physical architecture of the vehicle. }\end{array}$ & $\begin{array}{l}\text { Electronic system (not determined } \\
\text { by physical architecture) } \\
\text { Exhaust system (determined by } \\
\text { physical architecture) }\end{array}$ \\
\hline
\end{tabular}

There is a different climate in dealing with Ford. Years ago there was a better feeling or era of trust. Individuals within Ford were people of their word. You made an agreement, and people kept their word. Their word was good. Now, I do not do anything without having it in writing--I can't trust these people.

Another clear trend was a noticeable shift in relationship styles between OEMs and suppliers during the time frame in which the interviews were conducted (1998-2001). Data collected in the 1998-1999 time frame indicated a general shift from adversarial to partnerial models, and is consistent with much of the literature that came out in the 1990s concerning OEM/supplier relationship styles [2], [12], [42]. However, the evidence collected in 2000-2001, the second half of the time window, showed a distinct trend toward a hybrid between the two styles, with characteristics of the adversarial relationship style being dominant. This observation of the cyclical relational trend occurring between OEMs and suppliers will be analyzed in more depth later in the paper.

\section{Supplier Integration Models}

The traditional U.S. supplier management model existed for many decades and operates primarily as a functional organization (see Fig. 1).

There is a parent department such as the chassis department. This parent department is then further divided into more specialized functional departments such as suspension, steering, and braking. Each of these functions is assigned an OEM release engineer who interacts with the steering, suspension, and braking divisions of first-tier suppliers. The OEMs keep considerable control over individual components, in some cases, designing the component and sending the design out for bid to suppli- ers. They also act as program managers and systems integrators with department titles such as "systems engineering." In this capacity, the OEM directly coordinates the design and logistics efforts of their suppliers. As shown in Fig. 1, the functions that are deemed to be part of the OEM's vertical hierarchy are designated with solid lines, while the solid double-headed arrows symbolize the coordination requirements needed between the OEM and the Tier 1 suppliers.

Unlike the traditional U.S. supplier management model, the Japanese supplier model gives substantial responsibility for design to the suppliers. However, the organizational relationship between the OEM and its suppliers also tends to be functional, as in the U.S. supplier model case. The Japanese model is displayed in Fig. 2.

Since the OEM generally has equity ownership in the supplier that is given design responsibility, the Japanese supplier model is also termed the keiretsu model. As shown in the figure, the solid lines (as in the case of the traditional U.S. supplier model) designate the OEM's vertical hierarchy, whereas the dual solid arrows signify the stronger intimate and interlocking nature of the keiretsu relationships found in the Japanese model of supplier management.

As mentioned earlier, two additional forms of supplier management models were evident in the interviews. We describe these as emerging U.S. supplier models. These newly evolving models appear to take on two forms: the module supplier model and the systems integrator model. Based on the anecdotal evidence, it appears that the module supplier model is a transitional form, with the systems integrator model apparently being the desired future evolutionary form of the U.S. supplier model. Both the models vary from both the traditional U.S. and Japanese supplier management models in important ways. 


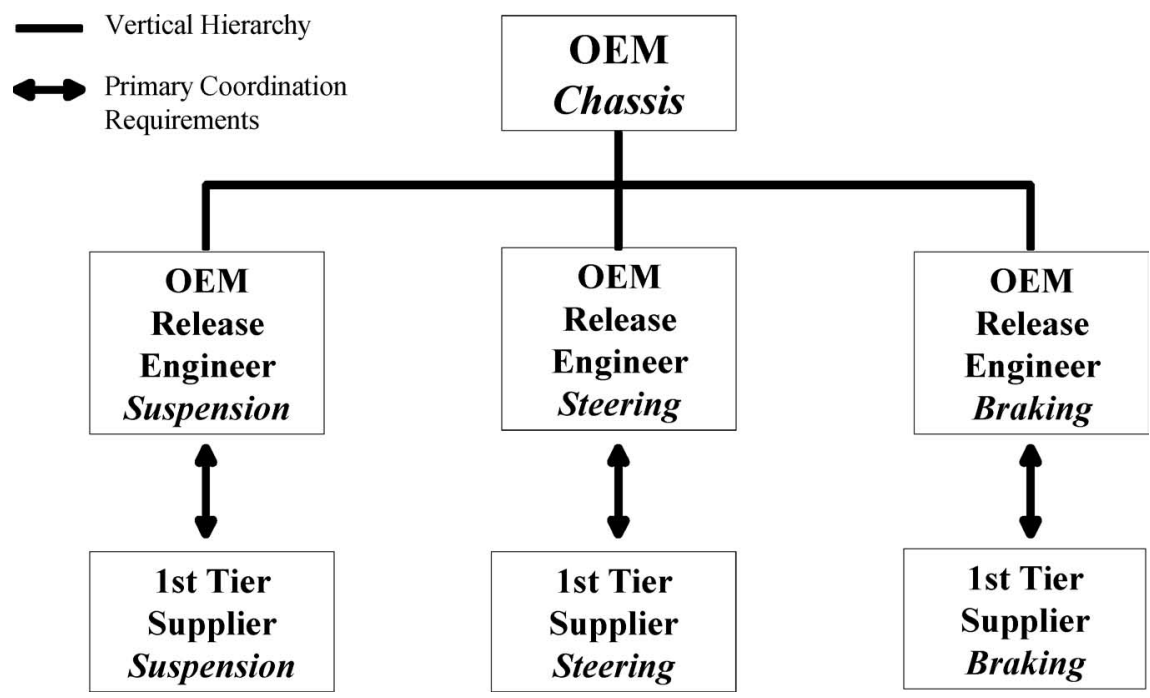

Fig. 1. Traditional U.S. supplier model.
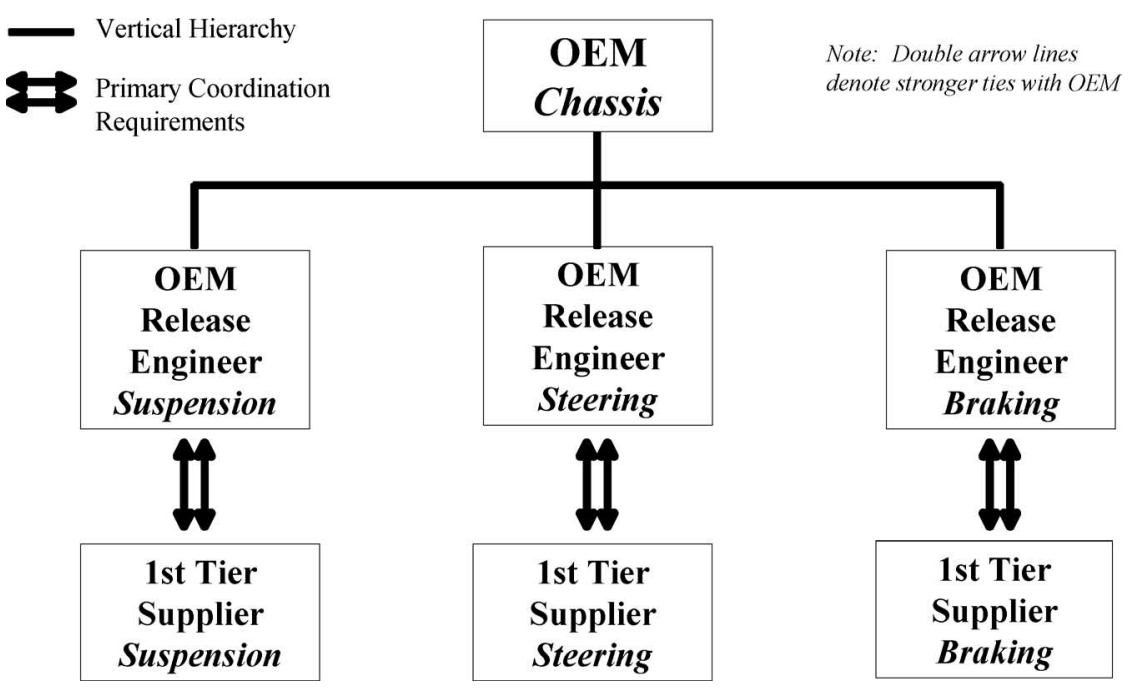

Fig. 2. Japanese keirestu supplier model.

\section{E. Module Supplier}

Although gaining mainstream popularity, the modular notion in the automotive industry was still in its infancy in North America at the time of the interviews. OEMs were going through a phase where they were trying to discover the best type of organization to adopt, both within themselves and their supply base, to maximize the benefits of modularity. The business development director of modules and systems of a leading chassis supplier pointed out that "At this point, there are still some differences across OEMs. Some try to add modularity over their existing organization, and it does not work well yet. In large part this is due to the fact that all the major OEMs in North America have buyers in the purchasing departments organized by component commodity groups, and modules can cut across those groups (e.g., braking, electrical, and chassis)."

The implication is that the functional organization is not compatible with a modular approach to product development. Since a bundle of responsibilities are shifted to the suppliers that are crossfunctional in nature, a product form of organization is needed. From our interviews, 10 of the 23 participating suppliers identified themselves as mature module suppliers, and another 12 reported that they were involved in some way with modular programs. Fig. 3 is a depiction of the module supplier model.

This module supplier model shows an important difference from the traditional U.S. supplier model. The presence of a module supplier (i.e., in Fig. 3, the module supplier is providing the corner module of a vehicle, which typically consists of the headlight, braking, suspension, and other components) requires coordination between the chassis OEM, and the first-tier suppliers. Other first-tier suppliers provide their parts to the module supplier, who may very well be another first-tier supplier. This module supplier then assembles a module that is to be sent to the OEM. Door panels and corners of a vehicle are common products that would fall into the module category. 


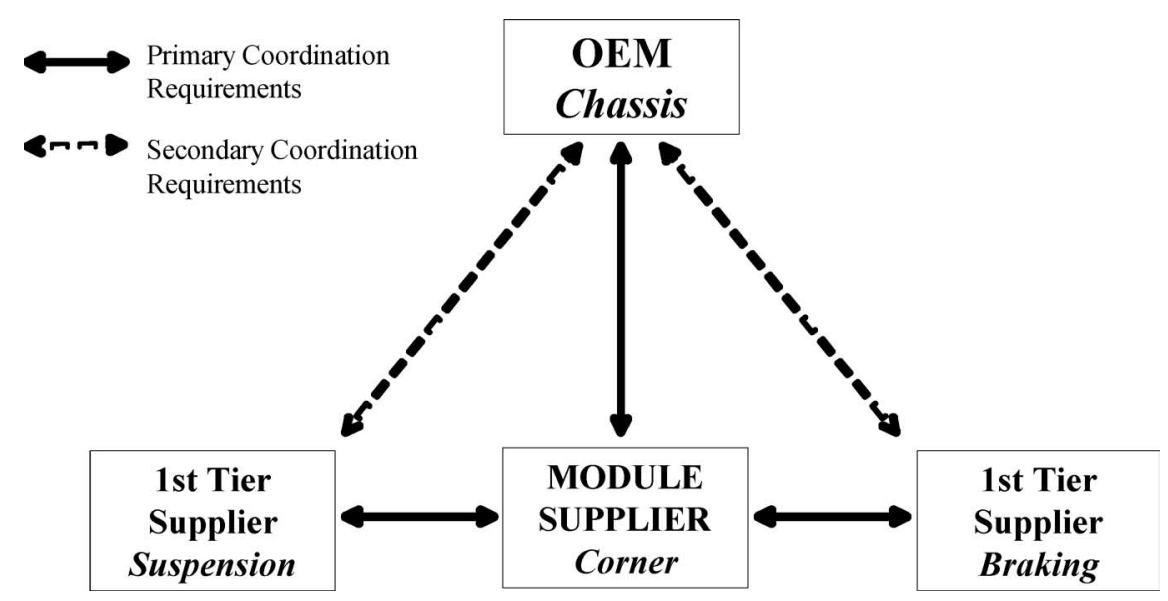

Fig. 3. Module supplier model.

In the module supplier model, we see that the module supplier serves as the primary point of contact with the OEM. Thus, the coordination requirements and flow of communication between the OEM and the module supplier is vitally important. The OEM may pass along design specifications and requirements across the coordination and communication channels. Gone are the functional chimneys prevalent in the traditional U.S. supplier model where the OEM is required to talk directly with each major supplier involved in a project through a release engineer. In the module supplier model, it is unnecessary for the OEM to have frequent direct contact with the other Tier 1 suppliers, although it may occur from time to time. Instead, it is the module supplier that works closely with the other suppliers and provides the coordination responsibility necessary to communicate with the other Tier 1 suppliers involved in the project. In Galbraith's [19] terms, the assumption is that the module has become a selfcontained task that can be managed relatively autonomously by the module supplier.

More specifically, module supplier responsibility is to keep the master design layout of the product, and to coordinate all the design activities of the other individual suppliers involved. The module supplier needs to stay in daily contact with all the individual suppliers, and is responsible for making sure all the differing parts fit together as a unit. As the business development director of modules and systems at a Tier 1 chassis system supplier indicated, "We're all sailing in the same direction .... Modules are a huge team effort not to only build a module, but to make the module fit the car."

The directors and managers interviewed saw modularity as an inevitable trend sweeping the automotive industry. "None of the OEMs want to be behind on the modularity bandwagon," asserts one product director. But, there are issues that do cause some concern about the popularity of modularity and its adoption into the automotive industry. This shift in responsibility requires a fundamental shift in roles and responsibilities, contractual relationships, supplier capability, and even a blending of organizational cultures. It was not clear to suppliers whether their customers were putting the cart before the horse in forcing modularity without working through these infrastructure requirements.

\section{F. Systems Integrator}

Within recent years, the term systems integration has become prevalent in the American automotive industry, particularly in the area of product development. Systems integration seriously pushes responsibility down to suppliers and promises to significantly reduce labor and overhead in OEM engineering organizations. In traditional product development, at least in the United States, the basic problem in planning coordination is that parts are interdependent yet developed by specialized engineering departments. Thus, intercomponent coordination within a project involves negotiations among several engineering groups. So, a change in one component tends to trigger countermeasures elsewhere, and the chain reaction of mutual adjustment makes coordination across the total vehicle time-consuming [34]. A key aspect of systems integration, on the other hand, is the ability of the lead supplier to manage and coordinate the design and assembly activities of large-scale modules and systems within the vehicle across a number of other suppliers, often times working in very close proximity with suppliers that may very well be competitors on other projects. About 10 of the 23 suppliers studied in this project identified themselves as systems integrator suppliers.

The realization of a systems perspective is important to ensure better designs and superior product performance. According to the product director of modules at a leading braking systems supplier:

\footnotetext{
A module in and of itself, is a combination of a lot of components. But we don't want to just assemble a bunch of pieces. We want these things to be value-added to a system. Many of these systems are going to talk to each other soon. The systems will be more interrelated. You need to handle synergy of design, synergy of performance. The module strategy is to develop module capability as a systems integrator. (The systems integrator) takes modules to another level compared to (other) people in the industry.
}

The newest type of supplier management model that we have observed is that that takes the role of managing systems integration, namely, the integrator supplier model. For all practical purposes, a systems integrator is an integrator supplier and is capable of managing large-scale programs for OEM customers. This is a fairly recent concept that has emerged in the United 


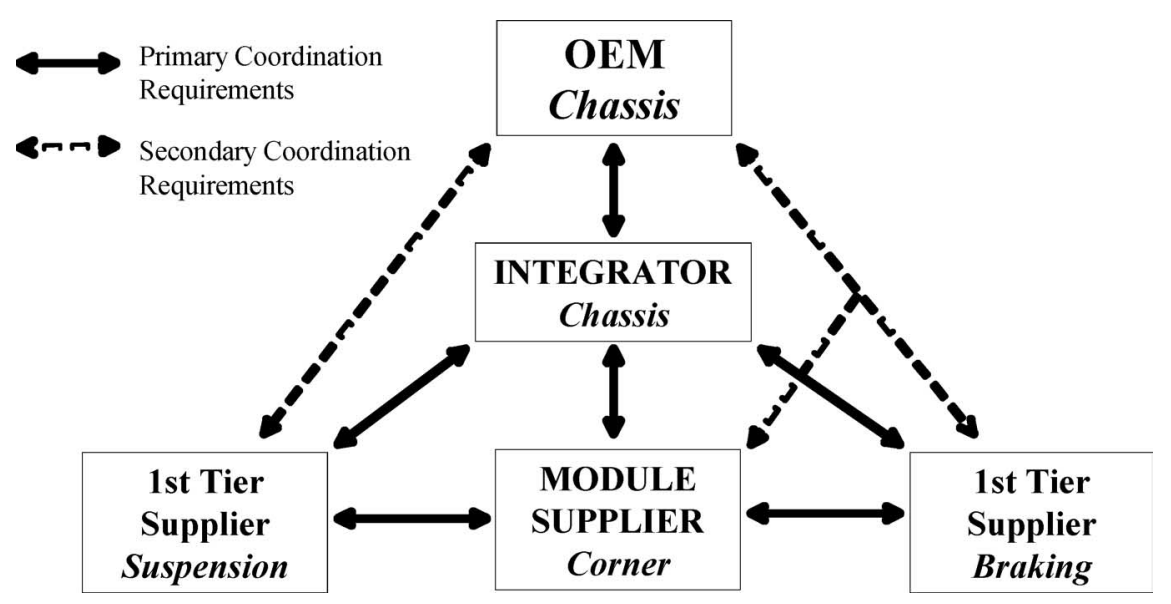

Fig. 4. Integrator supplier model.

States within the last decade, and has been called by such names as "Tier 0.5."

Due to the reciprocal task interdependence [18] that occurs when several suppliers work together on the design and assembly of large-scale modules, it is necessary for the integrator supplier model to address the coordination concerns that arise from such complex responsibility. In this particular model, the OEM creates self-contained tasks and a reduction of environmental complexity, much like in Galbraith's information processing model [19], by relinquishing much of the program management responsibility to the systems integrator. The systems integrator then becomes the primary point of contact with the OEM. Since the OEM only has to worry about communicating with a few systems integrators for any given vehicle program, the information processing requirements and communication channels are easier for the OEM to manage and oversee than a broad base of several dozen Tier 1 suppliers. The systems integrator, in turn, acts to reduce its own information processing and communication difficulties by creating stronger communication channels with the suppliers it has to work with through the use of more intimate lateral organizational relations such as direct contact and cooperative teams with the other suppliers involved in the project. The systems integrator thus manages the interdependence of all these tasks and communicates directly with the OEM throughout the development project (see Fig. 4). As Alexander Cutler, the President of Eaton Corporation, explained regarding Eaton's adoption of systems integration: "Give us the system design and hold us accountable for it. We'll sign up for that and we will create value for you" [43].

In the integrator supplier model, the systems integrator becomes the program manager for one or many systems within the vehicle program. The systems integrator is also responsible for the manufacture of the system though other suppliers, and even competitors may manufacture parts of the system. To a degree, the integrator supplier exerts direct control and influence over the first-tier suppliers involved on the project. In fact, the integrator supplier would coordinate the OEM's product design specifications and requirements, design change information, and even assembly requirements, such as information to bring the module line-side to the OEM assembly plant in timed sequence with the vehicles on the line. In turn, the systems integrator is directed by the OEM itself. However, as a precautionary measure, and as an added line of accountability, the OEM will most likely exert some form of control, or, at least, be in occasional contact with all the other first-tier suppliers.

The suppliers that are leading the systems efforts are often expected to house other suppliers in their R\&D facilities, even competitors in some cases. However, this depends on the size of the module or subsystem being designed, and on whether the suppliers' and OEM's facilities are within close proximity geographically. From the engineering design side of systems integration, there is a need for common facilities, equipment, and tools. There needs to be a central design house where all the design activities can take place. Other suppliers will be supplying equipment, computers, and tools as well. And, in some cases, the systems integrator can rent out the computers and the space. The key, however, seems to be the complexity of the technical interface between the component and the vehicle. Unlike a simple commodity part, the more that the component defines the character of the vehicle, the more communication and interaction between engineers in suppliers and OEMs is necessary.

Security and confidentiality issues also arise among suppliers when they act as systems integrators. It is an issue that is constantly being addressed since many times, the systems integrator will house competitive suppliers in-house within the same facilities as their own design teams. This close proximity allows for timely and direct communication and coordination, but stresses the need for security, especially since the lines of demarcation between competitive suppliers continually change from project to project. As the same product director of modules mentioned earlier describes, "You build fire walls to protect core technologies but for the betterment of the (OEM) customer, (all the suppliers) work together. For non-competing sub-suppliers, it is not an issue."

The question as to what motivates a supplier to become a systems integrator was met with a very interesting response. After all, the role of a systems integrator requires more work, planning, and coordinating. And OEMs are not willing to directly 


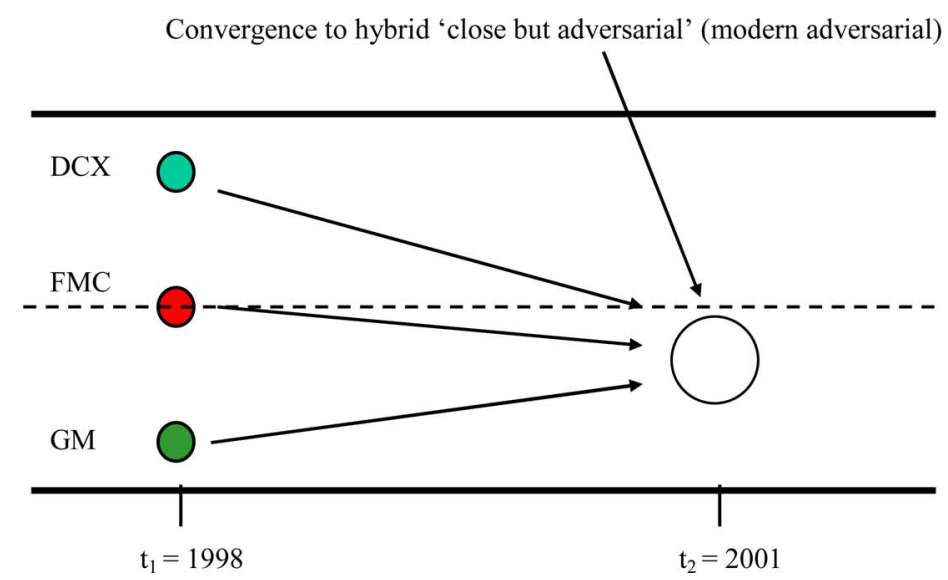

PARTNERIAL:

Technical autonomy

Long-term contracts

Minimal inspection

Technical support to suppliers
ADVERSARIAL:

Price pressure

Annual price reductions

Cost reduction workshop (PICOS)

Free R\&D

Fig. 5. U.S. buyer-supplier relationship mapping on partnerial versus adversarial dimension.

compensate the systems integrator for their total time or contributions. One of the directors at a Tier 1 interior systems supplier answered the question this way:

Being a systems integrator is more responsibility, but in the end it's a better position to be in. It's not a profit motive, but you get notoriety and a reputation. It does open up doors for you. (We) would opt to be the systems integrator if given a choice because we then call the shots and run the show.

Another director at the same supplier agreed:

\begin{abstract}
(Being a systems integrator) will not necessarily provide additional content, but it will give you control of the program. Your name may become better known for that particular vehicle. It raises our customers' awareness of (our company). We do not make money for being systems integrators .... We make money making parts. You do not do it to get more content, but to raise awareness.
\end{abstract}

Typically, suppliers who wish to be systems integrators cannot afford to do so unless they are directly supplying a large portion of the system. This is because of the cost constraints involved. As the director of program management at a Tier 1 supplier explains "Even though the integration costs are rolled back into the piece costs, the profit margins are so low that if the supplier had to roll the integration costs into just a few parts, it would not be feasible. So you need to be an integrator on a large commodity."

\section{G. Relationship Convergence}

Traditionally, Japanese OEM/supplier relationships were characterized as long-term partnerships. By contrast, U.S. OEM/supplier relationships were adversarial and characterized by heavy use of coercive bureaucratic mechanisms. As American companies in the 1990s worked to adopt aspects of the Japanese model, we observed a shift, with some firms moving closer than others to the Japanese model. In 1998, at the beginning of the interviews, Chrysler was the closest to the partnerial model, while GM remained closest to the traditional adversarial model (see Fig. 5).

As the study progressed, however, it became clear that there was a shifting when it came to the relationship styles between the U.S. OEMs and their suppliers. Characteristics of the adversarial style slowly became apparent as the more frequently used relationship style in the OEMs' dealings even with their "partner" suppliers. In a few of the later interviews occurring in the 2000-2001 time frame, there was complaining about how some OEMs that were less adversarial in their treatment of suppliers in the past were now becoming more antagonistic. In one of the interviews, the director of sales at a leading full service supplier explained his dealings with Ford in the following way:

\footnotetext{
Some customers are partnerships. Other customers could be more like extortion. Ford swings in the middle-of-the-road. They talk partnerships, but play the GM game. They award new business based on the Chrysler philosophy of partnering-up, but negotiate costs similar to GM; very aggressive and can get in your face.
}

With regard to the partnerial style that Chrysler has been known for in the past, especially in the days of former Chrysler President Stalkamp, the director quotes:

\footnotetext{
DaimlerChrysler is moving away from the partnership model somewhat. They are starting to entertain other suppliers, rather than their chosen suppliers. A lot of it has to do with their global capability. This is because DaimlerChrysler has some suppliers that are not capable of becoming global suppliers.
}

Out of all the American automakers in the 1990s, Chrysler was known to be the frontrunner when it came to implementing long-term partnerships with their suppliers. During this time, Chrysler was making strides in forging the partnership model with its key suppliers, even causing Chrysler and its suppliers to be referred to as an "American keiretsu" [38]. When asked by suppliers who did not have Chrysler business (but wanted to seek it out and quote Chrysler a business package), they were told in effect by Chrysler: "We are fully booked with our current suppliers. Talk to them about partnering." But, by the late 1990s and early 2000s, it became clear that DaimlerChrysler and other U.S. automakers were beginning to move back toward the adversarial relationship style with suppliers.

When Daimler-Benz acquired Chrysler in 1998, a major transition in leadership occurred that caused Chrysler to rethink its supplier management model. Chrysler, which then became DaimlerChrysler, reevaluated the whole extended enterprise program. When it was finally realized that GM and Ford were paying their suppliers less than what DaimlerChrysler was 


\title{
Near-Circular Adversarial-Partnerial Cycle: State of Buyer-Supplier Relationship Styles in the U.S. (from 1950-Present)
}

\author{
Old Adversarial (1950s-1980s) $\rightarrow$ Partnerial (1990s) $\rightarrow$ Modern Adversarial / \\ Hybrid (leaner but meaner) (2000-Present)
}

Old Adversarial (1950s-1980s)

Modern Adversarial / Hybrid (2000-Present)

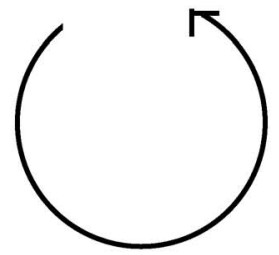

Partnerial (1990s)

Note: Picture above does not capture shift of design responsibility

Fig. 6. Cyclical nature of buyer-supplier relations in U.S. auto.

paying its suppliers, both the extended enterprise program and the SCORE program were terminated. Afterwards, DaimlerChrysler started to revert back to the Lopez model of awarding business to the lowest competent bidder.

In the late 1990s, Ford Motor Company was still incorporating aspects of the partnership style in their supplier management model, but was also investigating alternate forms of market bidding simultaneously. Carlos Mazzorin, who was Vice-President of Global Purchasing at the Ford Motor Company, was sharing savings with Ford's suppliers, and many of the lead suppliers created dedicated business units that would cater specifically to Ford's needs. While at the same time helping suppliers achieve savings, Ford began to investigate the use of the Internet for e-business and e-bidding. During the days of chief executive officer (CEO) Jacques Nasser, Ford learned of the cost targeting and annual cost reductions that the Japanese OEMs were requiring from their suppliers. Ford then adopted mandatory cost savings for its own supply base, requiring set annual costreduction programs be implemented by their suppliers. Eventually, within recent years, both Ford and DaimlerChrysler made major strides toward e-bidding, where cost alone, between qualified suppliers, was the determining factor in gaining customer business.

In light of the aforementioned examples and some of the interviews conducted for this study, the situation in the U.S. auto industry by 2002 was that although some characteristics of the partnerial model were still in place, there was an adversarial undertone to the OEM/supplier relationship. There is a type of duality occurring where OEMs are trying to develop their lead suppliers, yet are putting intense cost saving pressures on them. And, if the suppliers do not meet the demands of the buyers (OEMs), the buyers are likely to switch to another source. The increased formal commitment between buyers and suppliers over the 1990s in the U.S. automotive industry (such as sourcing modules and the creation of dedicated business units among the lead Tier 1 suppliers) has not been accompanied by a corresponding increase in informal forms of cooperation between parties [44]. The resulting hybrid form of relationship has been termed the "close but adversarial" form of buyer-supplier relationship [44] in the literature.

Fig. 5 shows the conceptual representation of the buyersupplier relationship style shift occurring in the U.S. auto industry within the 1998-2001 time frame. The new hybrid form of relationship style dominant today is termed the "modern adversarial" relationship style where some of the characteristics of the original adversarial style (use of price pressures, cost reductions, free $\mathrm{R} \& \mathrm{D}$, etc.) exist in the formal arrangements (long-term contracts, dedicated business divisions, etc.) created from the partnerial style.

In a sense, one could argue that the way OEMs interact with their suppliers has come nearly full circle. What began with adversarial buyer-supplier relationships as the norm in the U.S. auto industry for several decades (1950s-1980s) progressed to a more partnerial relationship style in the 1990s as the American companies were learning from the Japanese. And, at the turn of the century, when a tough competitive market created pressures for cost reduction, there appears to be a move toward many of the characteristics of the old adversarial relationship styles, with an emphasis once again on price pressures and mandatory cost reductions. But, with lean manufacturing and Six Sigma initiatives gaining popularity in the auto industry, companies are trying to streamline their in-house and supply chain operations by cutting out wasteful costs, material, and time, while, at the same time, fine tuning their product quality and improving their business and engineering processes. This creates an environment where the emphasis is no longer on cost alone (as business was often awarded many decades ago), but OEMs are going after the suppliers and insisting that they meet the demands of the customer from not only a cost perspective, but with shorter lead times and near-perfect quality. The result is a leaner but meaner 
PARTNERIAL:

Technical autonomy

Long-term contracts

Minimal inspection

Technical support to suppliers

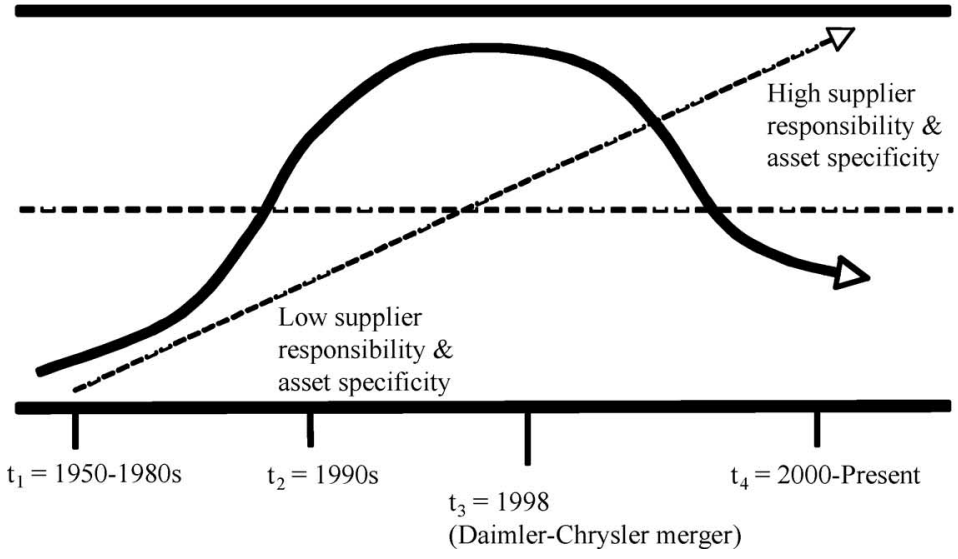

ADVERSARIAL:

Price pressure

Annual price reductions

Cost reduction workshop (PICOS)

Free R\&D

Fig. 7. Relationship evolution overtime.

modern adversarial form of buyer-supplier relationship seen among OEMs and suppliers today. Fig. 6 depicts this circular relationship.

It should be noted that the circular diagram in Fig. 6 only captures the relationship style and does not convey the shifting of design and engineering responsibility from the OEMs to the supply base that occurred over this same time period. In parallel with the outsourcing of design and engineering responsibility, there was also an increase in relationship-specific assets acquired by OEMs and suppliers during this same time frame. If both the shift in design responsibility and asset specificity were to be pictured overtime in conjunction with the changing buyersupplier relationship style, it could be depicted on the same conceptual adversarial-partnerial framework described earlier in Fig. 5. The last 50 years of the U.S. buyer-supplier relationship styles in the auto industry could then be mapped onto this framework as in Fig. 7.

Thus, the earlier years of OEM/supplier relationships in the U.S. auto industry can be described as being very adversarial in nature and accompanied with a low level of supplier design responsibility. Also, there were few relationship-specific asset investments in both hard assets (such as physical tools and equipment) and soft assets (such as technical knowledge and information processing capabilities) on either the OEM or supplier side. This state of affairs existed for quite some time until the 1980s when there began a significant move toward the partnerial form of buyer-supplier relationships accompanied with an increasing level of supplier design responsibility and greater investments in relationship specific assets. This trend persisted until about the end of the 20th century when the relationship style began to revert back to the adversarial form. However, the trend to outsource greater amounts of design responsibility to the supply base continued to increase in parallel with the asset specificity of the relationship, thereby creating the "close but adversarial" form of buyer-supplier relationships seen in the U.S. auto industry in the early 2000s.

By coming nearly full-circle and traversing the adversarial and partnerial continuum, the U.S. auto industry has shown that by this point in time, it has learned certain aspects of the
Japanese OEM/supplier relationship style. These aspects, characteristic of what is termed an enabling bureaucracy [23], create a partnerial buyer-supplier relationship and encourage suppliers to develop problem-solving competencies, become trained in the tools and knowledge relevant to the OEM customer, share control with the OEM in the design and development phase, participate in the strategic formulation process, and engage in collaborative control and learning between OEM and supplier. These characteristics of an enabling OEM/supplier bureaucracy include giving suppliers autonomy in the product design, encouragement of technical innovation, and ideas of continuous improvement, albeit in an American context.

However, the U.S. OEMs only learned selected features of the Japanese OEM/supplier relationship style: they are missing key features of this style that lead to organizational integration and aligned goals. Some features the U.S. auto industry has not adopted include the use of crossequity holdings between OEM and supplier, and the formal-legal control that this creates. American OEMs also tend not to extensively teach suppliers their product development systems, and instead, push increasing design responsibility down to the supply base. American OEMs do not develop suppliers or make the long-term commitments that engender trust and a sense of mutual destiny [2]. Yet, they have adopted mandatory annual cost reductions that put cost pressures on suppliers and have adopted characteristics of a coercive bureaucracy [23], which results in an adversarial buyer-supplier relationship style, and is characterized by the OEM working with several suppliers possessing narrowly defined specialized skills, and the OEM exercising unilateral top-down control of these suppliers. The process of formulating product strategy and concept tends to be very autocratic on the OEM's part, and exertion of strict control over suppliers through underlying market pressures also describe a coercive OEM/supplier bureaucracy. Such coercive OEM/supplier bureaucracies involve mandatory annual price reductions, expectations for the supplier to absorb R\&D costs, invasive micromanagement by the OEM into supplier design and production practices, and excessive cost-cutting pressures. 
TABLE V

JAPANESE MODEL VERSUS NEW EMERGING U.S. MODEL

\begin{tabular}{|l|c|c|}
\hline \multicolumn{2}{|c|}{ Japanese Model vs. New Emerging U.S. Model } \\
\hline \multicolumn{1}{|c|}{ Similarities } & Japanese Keiretsu Supplier & U.S. Systems Integrator \\
\hline Asset Investments: & Relationship specific & Relationship specific \\
\hline Supply Chain Structure: & Hybrid (make/buy) & Hybrid (make/buy) \\
\hline \multicolumn{1}{|c|}{ Differences } & Japanese Keiretsu Supplier & U.S. Systems Integrator \\
\hline Bureaucratic Mechanism: & Enabling & Coercive \\
\hline Responsibility: & Vertical coordination & \begin{tabular}{c} 
Manage competitors \\
\hline Role:
\end{tabular} \\
\hline Goal: & $\begin{array}{c}\text { Manage lower-tier suppliers } \\
\text { Meet target specifications } \\
\text { (cost \& technical) }\end{array}$ & \begin{tabular}{c} 
Meet OEM consumer expectations \\
\hline Link:
\end{tabular} \\
\hline
\end{tabular}

\section{DISCUSSION}

\section{A. Japan Model vs. Emerging U.S. Model}

Our interviews have shown that within the automotive industry, the modularity movement is coinciding with the U.S. supplier management model's deviation from the traditional Japanese supplier management model. Normally, for simple build-to-print components, Japanese OEMs tend to retain design control of much of the vehicle and delegate the manufacture and assembly of various components to their captive keiretsu suppliers. But, for major subsystems, Japanese OEMs tend to outsource the assembly (and in some cases, even the design) of more and more real estate in the automobile to top-tier suppliers.

The emerging U.S. model (which we have called the integrator supplier model), just as the Japanese model for the outsource of major subsystems, gives a great deal of design responsibility to first-tier suppliers. And the similarities do not stop there. Both models incorporate the use of relationship-specific assets. In the Japanese keiretsu, this takes shape in the investments in brick-and-mortar dedicated to the OEM customer as well as the time and resource intensive training that the OEM gives its suppliers. In the U.S. context, dedicated business units within the systems integrator devoted solely to the OEM customer and the use of resident engineers at the supplier facilities are examples of relationship-specific investments.

Both the models are also hybrids of hierarchy and market control structures. The U.S. systems integrator is an evolution from the traditional U.S. model with a Japanese-inspired flavor. In the case of GM and Ford, for decades, these American auto companies created nearly all of the vehicles they produced inhouse. The various components that were needed were produced by divisions internal within GM and Ford themselves. Then, in the 1999-2000 time frame, both GM and Ford sold off their parts supplier divisions, creating Delphi and Visteon. Both of these new companies had business units dedicated to their for- mer OEMs as well as other divisions that were responsible for getting other outside business. These new business units within Delphi and Visteon, and the other large megasuppliers, are U.S. hybrids. There may not be equity ownership or an interlocking board of directorates as in the Japanese case, but the dedicated business units within the suppliers cater wholly to the needs of the OEM with investments in relationship-specific assets being commonplace. At the same time, the OEM exerts cost pressures on the supplier, reminiscent of the adversarial style of buyersupplier relationship.

But not everything about these two models is similar; there are important differences. A comparison between the two models is summarized in Table V.

According to this comparison table, the bureaucratic mechanisms between the two models are quite different. As explained earlier in the paper, the Japanese OEM/supplier bureaucratic structure can be viewed as an enabling bureaucracy. Here, the structures and systems established in the relationship serve to facilitate the work and processes needed to effectively carry out performance objectives. Suppliers are trusted and empowered to make decisions that would better themselves and the customer. Collaborative interests between OEM and supplier exist due to the collateral ownership of the supplier, and the OEM invests a tremendous amount of time and resources into resources specific to the relationship such as training, equipment, technical tools, and processes. However, in the U.S. systems integrator role, the OEM/supplier bureaucratic structure resembles more of a coercive bureaucracy. In this type of bureaucracy, suppliers are guided into following protocol and the OEM's wishes through the use of authoritative hierarchy, procedure manuals, and financial pressure. The excessive cost reductions seen in the U.S. supplier management model benefit the OEM financially, but run the danger of putting the supplier out of business (as evidenced by the large number of Chapter 11 bankruptcy files of suppliers, including the GM spinoff, Delphi Corporation). And rarely is there deep loyalty to a supplier, resulting in an 
OEM/supplier relationship where deep integration and sharing of resources and knowledge does not occur.

The responsibility for overseeing Japanese first-tier suppliers lies in the vertical coordination that the OEM maintains, whereas in the new U.S. integrator supplier model, much of this responsibility belongs to the supplier selected as the systems integrator, and is thus more horizontal in focus. The role of the first-tier supplier in the Japanese keiretsu model is to manage lower-tier suppliers. But the new U.S. system integrator must devote time and energy to managing other suppliers, and even competitors, to successfully fulfill the desires of the customer. Some of these suppliers are lower-tier suppliers whom the firsttier supplier contracts with, and thus, has some formal control over. In other instances, they are competitors sharing a similar level of design responsibility. And, in certain cases, some are designated by the OEMs and directly contracted by the OEMs. This directed sourcing causes the systems integrator to have a certain degree of responsibility without formal authority.

There are also subtle but important differences in goals. The Japanese supplier tries to meet target specifications (e.g., weight, cost, and functional requirements), and satisfy the OEM on overall design quality. But, the Japanese OEM determines what the end customer wants and reflects these in specifications to the supplier. The U.S. systems integrator has this as a major responsibility, but is also concerned about meeting consumer expectations--defining what the end consumer wants. This is crucial if the integrator supplier wishes to improve its standing with its OEM customer, and to increase its reputation for quality products and services.

When so much responsibility is given to outside suppliers, OEMs must retain considerable control over their design activities. Much of the control of the OEM over the suppliers in the Japanese supplier model is keiretsu dependent; the OEM rarely gives a supplier outside of the existing keiretsu responsibility for key subsystems. Crossequity ownership within the keiretsu, mutual dependence on the keiretsu banking system, and the practice of sending OEM executives to become executives in key suppliers all serve to cement the control of the OEM over key suppliers [30], [45]. For OEMs and the U.S. integrator suppliers, the equivalent to this was historically direct control through ownership of parts operations. This, of course, did not guarantee that the internal parts operations would respond to bureaucratic control with efficient and competitive product development. Indeed, just a few years ago, it was common for OEMs to argue that their internal suppliers were "fat and happy" because they did not have to compete for business and were much less responsive to their parent's demand than were outside suppliers. So, these internal parts suppliers (Visteon and Delphi) became subsidiaries responsible for profit and loss, and in recent years, both Visteon and Delphi were spun off as separate companies. Thus, GM and Ford gave up the bureaucratic control that came with ownership.

Unlike keiretsu suppliers in Japan, outside supplier companies such as Delphi, Visteon, Lear, and Magna are first-tiers to almost all OEMs and not directly controlled by equity ownership or exclusive relationships. So, they have evolved dedicated business units assigned to Ford, GM, DaimlerChrysler, etc. They are often staffed by former managers from the customers who provide inside information and have extensive networks within the OEM. In some sense, this approximates the keiretsu ties in a decentralized way within the outside supplier.

However, ownership is not the only issue. When buyers and suppliers engage in a relationship over a long period, it is very likely that the buyer and supplier will become familiar with each other's behavioral tendencies. This will be particularly important for the buying firm, since the information asymmetry that increases the need for performance monitoring will be reduced [11]. The longer the relationship lasts, the stronger the bonds of trust and commitment that bind the buyer and seller into a close, collaborative relationship [46]. Japanese automakers, by investing overtime in partnerial relationships, develop relational characteristics that mitigate risks of exploitation of the supplier. Japanese OEMs expect open information sharing, even on suppliers' costs, and the supplier makes sufficient relationshipspecific investments so that long-term costs of opportunistic behavior in lost future business outweigh the short-term benefits.

When considering how the Japanese supplier management model is being transplanted here in the U.S., one must realize that recontextualization is likely to occur and that the transplanted model or concept may actually take on a different form in a foreign environment [4]. From our interviews, it became obvious that there were three basic relational barriers that created an environment nonconducive for a direct transference of the Japanese model here in the U.S., and thus, has caused the U.S. auto industry to respond with new emerging forms such as the module supplier model and the integrator supplier model.

The first barrier involves the practice of the awarding of projects based on competitive bidding, where business is awarded to the lowest bidder. This still tends to be a common form of supplier selection in the United States, extending to e-bidding. According to the interviewees in this study, an OEM will give the incumbent supplier a chance to match the lowest bidder price, but if the incumbent cannot match or beat it, the OEM will award the business to the lowest bidder. This may reduce costs for the OEM in the short term, but there are some drawbacks to this type of relationship. There is little advantage for the incumbent supplier to put forth the best effort in meeting targets, and certainly not in investing in innovation, since the awarded business may easily go to someone else. Also, the excessive cost-reduction policies put additional pressure on an incumbent supplier to reduce their profit margins considerably. This weakens the long-term economic viability of the supplier, leading to the rash of Chapter 11 bankruptcy filings the industry has seen.

The second major observed barrier was within the area of general trust issues. This can take form in many ways. First, the aforementioned competitive bidding policies cause a lack of trust between the supplier and the OEM and little desire to invest in customer-specific R\&D, thereby hindering mutual cooperation that would benefit the OEM/supplier relationship in the long run. When the OEM micromanages Tier 2 suppliers, it is again conveying a message of distrust to the first-tier suppliers. There is a leap of faith required in entrusting Tier 1 suppliers 
to develop proprietary product designs for the OEM and for the supplier to share proprietary technology with the OEM. Since in the integrator supplier model, systems integrators are moving more and more upstream in the product development process, trust issues need to be taken seriously. Eventually, systems integrators may well become "involved with the end customer, so they will have to find a way to bridge these trust gaps" [43].

The third and final type of observed barrier is that of poor coordination and communication between OEM and suppliers. Based upon the information gathered in our interviews, there seems to be a lack of internal coordination inside the OEM regarding decisions concerning the supplier. There also seems to be a lack of communication regarding issues such as lastminute design changes, causing frustration on the supplier's part, and confusion on the OEM's part. There is also no timely commitment for heavy investments (e.g., tooling). Often times, the OEM's commitment to the supplier and the design comes after the supplier is well into the design and even production phases of the project.

\section{B. Dominant Model?}

Over decades, the Japanese OEMs and their keiretsu suppliers increased their information processing capabilities [19]. American companies sought the cost benefits of efficient suppliers who take on engineering responsibility without the investment in an enabling infrastructure. But there is an inherent misfit between coercive mechanisms and task interdependence [18] and asset specificity in this model, creating a hodge-podge collection of selected features from the Japanese supplier management model intermingled with aspects of the old traditional U.S. supplier model. The Japanese have evolved a hybrid of market and hierarchy, but the U.S. companies are using a dysfunctional hybrid and are missing the control and enabling features that are part of the Japanese model. The Japanese OEMs are able to keep control by buying part of the supplier, but the American OEMs do not have the leverage provided by equity holdings in their suppliers. So instead, they turn to market and cost pressures to get the suppliers to do what they want. The Japanese have facilitated knowledge and resource transfer by acquiring their suppliers, which is consistent with some of the thinking found in resource-based theories [15]. By not acquiring their suppliers, American OEMs have a more difficult task of transferring these same things.

What the U.S. supplier management model does do well, however, is exert business control in a hierarchy. American OEMs are good at controlling suppliers through purchasing and market power and independent business units. They exert business control in a simulated hierarchy, so even though the suppliers are not owned by the OEM, the relationship is set up in a way such that the supplier is more strongly tied to the OEM than in the past traditional U.S. supplier management configuration. But unless the organizational integration issues are addressed, the United States' failing will be on the technical integration side. They will get good cost reductions, but at the expense of systems integration that leads to the highest quality automobiles.
The result is also financially weakened suppliers that cannot invest in the R\&D required by this new business model.

\section{CONCLUSION}

\section{A. Limitations of the Study}

Due to the exploratory nature of the research questions, the use of qualitative interviews was employed throughout the course of the study. This allowed for a rich and descriptive set of anecdotal data concerning the evolution of supplier management models and relational typologies that exist between buyers and suppliers in the U.S. auto industry. Although rich in details, the open-ended interview format limited opportunities for formally testing hypotheses. This, and other limitations, need to be kept in mind when considering the findings in this study.

One issue to consider is the limits of generalizability of the results of the study. The findings found in the study apply specifically to supply management practices in the auto industry. This being said, the recontextualization of Japanese supplier management practices in the U.S. auto industry provides an interesting and informative contextual picture with regard to the types of issues that may arise due to existing firm structures and practices in the context of transferring practices across national borders.

Another limitation deals with the response bias issue [47]. Interviews conducted with OEMs represented a smaller portion of the collected interviews, with automotive suppliers providing the larger portion of data. Some reasons exist for this. First, there are far fewer OEMs than suppliers existing in the auto industry. Also, the setting up of interviews with supplier firms was less problematic than the setting up of interviews with automakers. Due to the sheer number of Tier 1 suppliers in the auto industry and the ease of access to them, interviews with suppliers were readily available. However, with the automakers, we ran into many barriers in setting up interviews. Reasons for this could have been a lack of willingness to be interviewed on the part of the OEMs and the necessity for bureaucratic approval on multiple departmental levels within the OEMs. Regardless, it would have been preferable to conduct more interviews at other OEMs to establish greater validity and consistency across the OEM perspective and negate any skewing toward the perspective of the suppliers.

Finally, gathering further information from alternative data sources such as the use of a survey or secondary archival data could provide additional evidence to substantiate further more of the claims in the paper and provide more details regarding the supplier management and firm relationship developments occurring in the auto industry.

\section{B. Future Direction and Concluding Remarks}

As a result of this investigation, we have seen significant involvement of suppliers in design in the U.S. auto industry. It appears that the number of suppliers getting involved in product design is growing at an increasing rate, and will only continue to do so in the near future. It should be noted that the Japanese supplier model served as a starting point, or benchmark, for the supplier models that have been witnessed emerging here in the 
United States; a combination of module supplier and systems integrator roles. The U.S. OEM purchasing strategy is still in a state of transition and a hybrid of market control and relational contracting.

With the emergence of the module and integrator supplier models in the U.S. auto industry, there is a danger that the Big 3 approach to supplier management will become the dominant organizational design in America. Also, with the forming of the "close but adversarial" style of OEM/supplier relationships in recent years, the influence of the old ways of doing business are still alive and well even after all the lessons learned in the 1990s at doing business in a more paternerial way. Old ways are hard to change, and paradigms have a constraining effect. The U.S. supplier management model has broken technical and organizational systems that will not go away just by coercive market forces. The underlying systems problem is still there and it is this underlying problem that is more difficult and challenging to fix.

Future research on this topic is needed to investigate further the ongoing evolution of supplier management models in the United States and on how modularity and systems integration will mature in the U.S. automotive industry context. If integrator suppliers are truly the higher evolutionary form, then we should see the lead Tier 1 suppliers continuing to dominate this position with their program management capabilities and taking the lead on projects with coordination oversight over both module and component suppliers. A greater discrepancy in the amount of design responsibility should also continue to occur between the integrator suppliers and the rest of the supply base.

This then brings up another question of power relationships between the lead Tier 1 integrator suppliers and the OEMs themselves. In the future, as the outsourcing of product development and coordination responsibilities to the supply base increases, do the relationships between the OEMs and systems integrators become more antagonistic as early trends indicate? Since systems integrators are buying up competencies to handle the growing amount of responsibility that they have over larger and larger pieces of vehicle real estate, is this also leading to an increase in power or leverage in relation to the OEMs? Will this be a threat to the brand recognition or OEMs' leverage over some suppliers? How much of the "Intel Inside" phenomenon will happen in the auto industry? Several years ago, Intel practically became a household name with their "Intel Inside" logo campaign. The logo was pasted on every PC that contained an Intel microchip as a stamp of technical and quality credibility. Consumers and businesses everywhere soon began buying PCs that had the logo stamped on the computer body. And soon, the brand recognition of Intel began to overshadow the brands of the PCs themselves. Will the same trend that we saw with Intel in the personal computer industry happen in the automotive industry? Then how would the OEMs differentiate themselves?

As stated in this paper, recent mergers occurring among automotive suppliers are reducing the supply base and are reducing the differentiation between OEMs. There is also a growing movement among OEMs to move more toward acting like marketing, assembly, and distribution systems, while relinquishing more of the manufacturing and production responsibilities to first-tier suppliers. There have been substantial efforts on the part of American OEMs to try and optimize their customer/supplier relationships. Of course, the barriers that exist are challenges that will need to be overcome. But, as time progresses, it is quite clear that although the U.S. auto industry began at a point where it was copying the Japanese model of supplier management, the model has mutated into a different form of hybrid. And in the cases of modularity and systems integration, they are deviating from the traditional Japanese model with both positive and negative impacts and turning into something much more distinctly American.

\section{REFERENCES}

[1] C. H. Fine, Clockspeed: Winning Industry Control in the Age of Temporary Advantage. Reading, MA: Perseus, 1998.

[2] R. R. Kamath and J. K. Liker, "A second look at Japanese product development," Harvard Bus. Rev., vol. 72, no. 6, pp. 154-170, 1994.

[3] J. H. Dyer, "Specialized supplier networks as a source of competitive advantage: Evidence from the auto industry," Strategic Manage. J., vol. 17, no. 4, pp. 271-291, 1996.

[4] J. K. Liker, M. Fruin, and P. S. Adler, Remade in America: Transplanting and Transforming Japanese Management Systems. New York, NY: Oxford Univ. Press, 1999.

[5] J. F. Krafcik, "Comparative analysis of performance indicators at world auto assembly plants" M.S. thesis,, Sloan School Manage.Massachusetts Inst. Technol., Cambridge, MA, 1988.

[6] J. P. MacDuffie and F. K. Pil, "High-involvement work systems and manufacturing performance: The diffusion of lean production in the world auto industry," Working paper, Dep. Management, Wharton School, Univ.. Pennsylvania, Philadelphia, PA, 1988.

[7] M. Erez, "The congruence of goal-setting strategies with socio-cultural values and its effect on performance," J. Manage., vol. 12, no. 4, pp. 585$592,1986$.

[8] T. Morris and C. Pavett, "Management style and productivity in two cultures," J. Int. Bus. Stud., vol. 23, no. 1, pp. 169-179, 1992.

[9] M. T. Brannen and J. M. Wilson III, "Recontextualization and internationalization: Lessons in transcultural materialism from the Walt Disney Company," CEMS Bus. Rev., vol. 1, 1st ed., pp. 97-110, Mar. 1996.

[10] O. E. Williamson, "The economics of organization: The transaction cost approach," Amer. J. Sociol., vol. 87, no. 3, pp. 548-577, 1981.

[11] K. Eisenhardt, "Agency theory: An assessment and review," Acad. Manage. Rev., vol. 14, no. 1, pp. 57-74, 1989.

[12] J. H. Dyer and W. G. Ouchi, "Japanese-style partnerships: Giving companies a competitive edge," Sloan Manage. Rev., vol. 35, no. 1, pp. 51-63, 1993.

[13] M. Aoki, Information, Incentives, and Bargaining in the Japanese Economy. Cambridge, MA: Cambridge Univ. Press, 1988.

[14] J. H. Dyer and H. Singh, "The relational view: Cooperative strategy and sources of interorganizational competitive advantage," Acad. Manage. Rev., vol. 23, no. 4, pp. 660-679, 1998.

[15] J. Barney, "Firm resources and sustained competitive advantage," $J$. Manage., vol. 17, no. 1, pp. 99-120, 1991.

[16] S. D. Hunt, A General Theory of Competition: Resources, Competences, Productivity, and Economic Growth. Thousand Oaks, CA: Sage, 2000.

[17] B. Wernerfelt, "A resource-based view of the firm," Strategic Manage. J., vol. 5, no. 2, pp. 171-180, 1984.

[18] J. Thompson, Organizations in Action. New York: McGraw-Hill, 1967.

[19] J. R. Galbraith, Organization Design. Reading, MA: Addison-Wesley, 1977.

[20] S. K. Fixson, "Product architecture assessment: A tool to link product, process, and supply chain design decisions," J. Oper. Manage., vol. 23, no. 3/4, pp. 345-369, 2005.

[21] J. H. Mikkola and O. Gassmann, "Managing modularity of product architectures: Toward an integrated theory," IEEE Trans. Eng. Manage., vol. 50, no. 2, pp. 204-218, Mar. 2003.

[22] M. A. Schilling, "Towards a general modular systems theory and its application to interfirm product modularity," Acad. Manage. Rev., vol. 25, no. 2, pp. 312-334, 2000.

[23] P. S. Adler, "Building better bureaucracies," Acad. Manage. Executive, vol. 13, no. 4, pp. 36-47, 1999. 
[24] J. K. Liker, R. R. Kamath, S. N. Wasti, and M. Nagamichi, "Supplier involvement in automotive component design: Are there really large US Japan differences?," Res. Policy, vol. 25, no. 1, pp. 59-89, 1996.

[25] J. H. Dyer, "Dedicated assets: Japan's manufacturing edge," Harvard Bus. Rev., vol. 72, no. 6, pp. 4-8, 1994.

[26] K. B. Clark and T. Fujimoto, "Lead time in automobile product development explaining the Japanese advantage," J. Eng. Technol. Manage., vol. 6, no. 1, pp. 25-58, 1989.

[27] M. A. Cusumano and A. Takeishi, "Supplier relations and management: A survey of Japanese, Japanese-transplant, and U.S. auto plants," Strategic Manage. J., vol. 12, no. 7, pp. 563-588, 1991.

[28] M. Sako and S. Helper, "Determinants of trust in supplier relationships: Evidence from the automotive industry in Japan and the United States,", J. Econ. Behav. Organ., vol. 34, no. 3, pp. 387-417, 1998.

[29] D. Sobek, J. K. Liker, and A. Ward, "Another look at how Toyota integrates product development," Harvard Bus. Rev., vol. 76, no. 4, pp. 36-50, 1998.

[30] M. J. Smitka, Competitive Ties: Subcontracting in the Japanese Automotive Industry. New York, NY: Columbia Univ. Press, 1991.

[31] T. Nishiguchi, Strategic Industrial Sourcing: The Japanese Advantage. New York, NY: Oxford Univ. Press, 1994.

[32] M. Bensaou and E. Anderson, "Buyer-supplier relations in industrial markets: When do buyers risk making idiosyncratic investments?," Organ. Sci., vol. 10, no. 4, pp. 460-481, 1999.

[33] J. P. Womack, D. Jones, and D. Roos, The Machine That Changed the World. New York, NY: Rawson Associates/MacMillan, 1990.

[34] K. B. Clark and T. Fujimoto, Product Development Performance: Strategy, Organization, and Management in the World Auto Industry. Boston, MA: Harvard Business School Press, 1991.

[35] S. Helper, "How much has really changed between U.S. automakers and their suppliers?," Sloan Manage. Rev., vol. 32, no. 4, pp. 15-28, 1991.

[36] Y. K. Ro, J. K. Liker, and S. K. Fixson, "Modularity as a strategy for supply chain coordination: The case of U.S. auto," IEEE Trans. Eng. Manage., vol. 54, no. 1, pp. 172-189, Feb. 2007.

[37] B. Vlasic, D. Howes, and M. Truby, "Lopez indicted in GM theft," The Detroit News, May 23, 2000.

[38] J. H. Dyer, "How Chrysler created an American keiretsu," Harvard Bus. Rev., vol. 74, no. 4, pp. 42-56, 1996.

[39] Michael F. Corbett and Associates, Ltd., "Chryster Corporation Shoots and SCOREs: A Case Study." International Association of Outsourcing Professionals, 2002, (IAOP) [Online]. Available: http://www.firmbuilder.com

[40] J. H. Sheridan, "Suppliers: Partners in prosperity," Industry Week, pp. 1219, Mar. 19, 1990.

[41] M. Sako, Prices, Quality and Trust: Inter-Firm Relations in Britain and Japan. Cambridge, U.K.: Cambridge Univ. Press, 1992.

[42] S. R. Helper and M. Sako, "Supplier relations in Japan and the United States: Are they converging?," Sloan Manage. Rev., vol. 36, no. 3, pp. 7784, 1995.

[43] Automotive Industry, Jul. 1999, p. 52.

[44] R. Mudambi and S. Helper, "The "close but adversarial' model of supplier relations in the U.S. auto indultry," Strategic Manage. J., vol. 19, no. 8, pp. 775-792, 1998.

[45] K. Shimokawa, "Japan's keiretsu system: The case of the automobile industry," Jpn. Econ. Stud., vol. 13, pp. 3-31, 1985.

[46] V. Sriram and V. Mummalaneni, "Determinants of source loyalty in buyersupplier relationships," Int. J. Purchasing Mater. Manage., vol. 26, no. 4, pp. 21-26, 1990.

[47] R. K. Yin, Case Study Research:Design and Methods, 2nd ed. Thousand Oaks, CA: Sage, 1994.

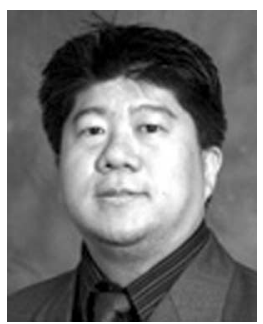

Young K. Ro received the B.S. and M.S. degrees in industrial engineering from Purdue University, West Lafayette, IN, and the Ph.D. degree in industrial and operations engineering from the University of Michigan.

$\mathrm{He}$ is an Assistant Professor of Operations Management at the University of Michigan, Dearborn. His work experience includes various positions at Intel Corporation, Eli Lilly \& Company, and TRW Automotive. At present, he is engaged in several research projects concerning the role of product architecture and decision-making agents in supply chain firm relationships within various industries as well as pedagogical work on learning outcomes in business education. His work has been published in journals such as the IEEE TRANSACTIONS ON ENGINEERING MANAGEMENT, International Journal of Automotive Technology \& Management, International Journal of Manufacturing Technology \& Management, Journal of Managerial Issues, Journal of Business \& Management, and the Decision Sciences Journal of Innovative Education, among others. His current research interests include supply chain management, product development, and the management of technology.

Dr. Ro is a member of the Academy of Management, the Decision Sciences Institute, INFORMS, and the Production \& Operations Management Society.

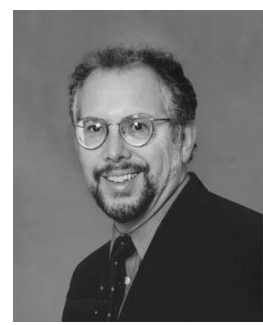

Jeffrey K. Liker received the B.S. degree in industrial engineering from Northeastern University, Boston, MA, and the Ph.D. degree in sociology from the University of Massachusetts.

He is Professor of Industrial and Operations Engineering at the University of Michigan, Dearborn. He has authored or coauthored over 75 articles and book chapters and seven books. He is the author of the international bestseller The Toyota Way:14 Management Principles from the World's Greatest Manufacturer (McGraw-Hill, 2004), The Toyota Way Fieldbook (McGraw-Hill, 2005), and The Toyota Product Development System (with James Morgan) (Productivity Press, 2006) - all three are winners of the Shingo Prize for Manufacturing Research Excellence.

Dr. Liker is Department Editor of Manufacturing Systems for the IEEE TRANSACTIONS ON ENGINEERING MANAGEMENT.

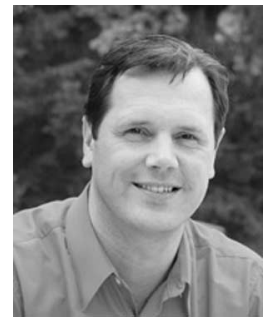

Sebastian K. Fixson received the degree of DiplomIngenieur (M.Sc.) in mechanical engineering from the University of Karlsruhe, Karlsruhe, Germany, and the Ph.D. degree in technology, management, and policy from Massachusetts Institute of Technology (MIT), Cambridge.

After graduation from MIT he joined the faculty of the Industrial and Operations Engineering department at the University of Michigan. He is currently a Visiting Assistant Professor at the MIT Sloan School of Management. His research interests include technology and innovation management and operations management in the product development context. In his recent research he focuses on the intersection of technical design decisions, such as modularity and product architecture, and organizational design decisions, such as process structure and granularity, and their joint effects on both strategic and operational performance. His work has appeared in books and journals including the Journal of Operations Management, IEEE TRANSACTIONS ON ENGINEERING MANAGEMENT, Concurrent Engineering, and Technological Forecasting and Social Change.

Dr. Fixson is a member of the Academy of Management, INFORMS, and POMS. He has recently served as chair of the Technology Management Section at INFORMS. 